OPEN ACCESS

Edited by:

Paul Evans,

The University of Sheffield,

United Kingdom

Reviewed by:

Stephen John White,

Manchester Metropolitan University,

United Kingdom

Nhat Tu Le

Houston Methodist Research Institute,

United States

*Correspondence:

Hui-li Lin

linhuilijinan@aliyun.com

Shu Lin

shulin1956@126.com

Specialty section:

This article was submitted to

Atherosclerosis and Vascular

Medicine,

a section of the journal

Frontiers in Cardiovascular Medicine

Received: 18 November 2020

Accepted: 03 February 2021

Published: 23 February 2021

Citation:

Zheng Y-I, Wang W-d, Li M-m, Lin S and $\mathrm{Lin} \mathrm{H}-\mathrm{I}$ (2021) Updated Role of Neuropeptide Y in Nicotine-Induced Endothelial Dysfunction and

Atherosclerosis.

Front. Cardiovasc. Med. 8:630968.

doi: $10.3389 /$ fcrm.2021.630968

\section{Updated Role of Neuropeptide $Y$ in Nicotine-Induced Endothelial Dysfunction and Atherosclerosis}

\author{
Yan-li Zheng ${ }^{1}$, Wan-da Wang ${ }^{1}$, Mei-mei Li ${ }^{1}$, Shu Lin ${ }^{1,2,3 *}$ and Hui-li Lin ${ }^{1 *}$ \\ ${ }^{1}$ Department of Cardiology, The Second Affiliated Hospital of Fujian Medical University, Quanzhou, China, ${ }^{2}$ Centre of \\ Neurological and Metabolic Research, The Second Affiliated Hospital of Fujian Medical University, Quanzhou, China, \\ ${ }^{3}$ Diabetes and Metabolism Division, Garvan Institute of Medical Research, Sydney, NSW, Australia
}

Cardiovascular disease is the leading cause of death worldwide. Endothelial dysfunction of the arterial vasculature plays a pivotal role in cardiovascular pathogenesis. Nicotine-induced endothelial dysfunction substantially contributes to the development of arteriosclerotic cardiovascular disease. Nicotine promotes oxidative inflammation, thrombosis, pathological angiogenesis, and vasoconstriction, and induces insulin resistance. However, the exact mechanism through which nicotine induces endothelial dysfunction remains unclear. Neuropeptide $Y(N P Y)$ is widely distributed in the central nervous system and peripheral tissues, and it participates in the pathogenesis of atherosclerosis by regulating vasoconstriction, energy metabolism, local plaque inflammatory response, activation and aggregation of platelets, and stress and anxiety-related emotion. Nicotine can increase the expression of NPY, suggesting that NPY is involved in nicotine-induced endothelial dysfunction. Herein, we present an updated review of the possible mechanisms of nicotine-induced atherosclerosis, with a focus on endothelial cell dysfunction associated with nicotine and NPY.

Keywords: neuropeptide Y, nicotine, endothelial dysfunction, atherosclerosis, cardiovascular disease

\section{INTRODUCTION}

Smoking is a serious global public health problem and an independent risk factor for cardiovascular disease. Nicotine is the main toxic substance in tobacco. Nicotine can induce endothelial dysfunction, which may lead to pathophysiological states contributing to the development of vascular disorders resulting from atherosclerosis (AS). Although nicotine-induced vascular endothelial dysfunction has been characterized, the mechanism has not been fully elucidated (1). Accumulated evidence has found that after nicotine exposure, the expression level of central and peripheral neuropeptide Y (NPY) changes. For example, NPY mRNA expression increased substantially in the hypothalamus of rodents administered the same dose of nicotine as that consumed by ordinary smokers $(2,3)$. Nicotine-induced noradrenaline (NA) release in perfused guinea pig hearts is accompanied by NPY overflow in the coronary venous system (4). The NPY system is strongly associated with arteriosclerotic cardiovascular disease. The binding of NPY to the Y1 receptor may be involved in the pathogenesis of chronic methamphetamine-induced AS (5). Therefore, NPY regulation plays a decisive role in the development of cardiovascular disease. There is increasing evidence that nicotine can cause disordered blood flow, which can induce endothelial dysfunction. Moreover, NPY can induce blood flow disorders through a variety of pathophysiological changes. NPY and nicotine may play a combined role in promoting endothelial 
dysfunction. The correlation between NPY and nicotine exposure-associated endothelial dysfunction and the underlying mechanisms are unknown. This review examines the role of NPY in nicotine-induced endothelial dysfunction, with a focus on the relationship between the nicotine/NPY system and the occurrence and development of arteriosclerotic cardiovascular disease.

\section{VASCULAR ENDOTHELIAL FUNCTION}

Endothelial cells (ECs) in the heart and vascular system, serve as important barriers between the blood and vascular walls and are innervated by sympathetic and parasympathetic nerves. In addition to playing a vital role in normal angiogenesis, dynamic balance, and vascular tone regulation, the endothelium is also an important metabolic and secretory organ. Endothelial products, including nitric oxide synthases (NOS), hydrogen sulfide, prostacyclin, endothelins, and thromboxane A2 (TXA2), affect the contraction and dilation of human blood vessels (6). NOS, comprising endothelial NOS (eNOS), neuronal NOS (nNOS), and inducible NOS (iNOS) are critical enzymes in nitric oxide (NO) production (7). ECs prevent arteriosclerotic cardiovascular disease by maintaining the delicate balance between hemorrhage and thrombosis by inducing the expression of coagulation factors and anticoagulants such as tissue factor (TF), von Willebrand factor, and fibrinolytic components; enhancing endogenous antioxidant capacity, especially the secretion of eNOS; promoting angiogenesis by secreting angiogenic growth factors, such as vascular endothelial growth factor (VEGF) and fibroblast growth factor; organizing immune cell recruitment by secreting chemokines and adhesion molecules; and transporting nutrients and signals. The physiological function of the circulatory system thus depends on the structural integrity of the endothelium.

\section{NICOTINE AND ENDOTHELIAL FUNCTION}

Nicotine can increase the release of neurotransmitters, particularly aminergic substances such as NA by stimulating nicotinic acetylcholinergic receptors (nAChR) that mainly act on chromaffin and nerve cells. The physiological form of nicotine not only induces angiogenesis, mediated by nAChR effects on ECs, but also promotes EC mitosis by inducing the secretion of angiogenic factors $(8,9)$. Nicotine stimulates the production of reactive oxygen species (ROS) that activate scavenger receptors, and ultimately lead to leukocyte adhesion and increased cell permeability. Nicotine does not merely reduce the secretion and bioavailability of $\mathrm{NO}$ by promoting eNOS uncoupling and changing the mitochondrial electron transport chain (10), it also affects the secretion of insulin and glucagon, which

Abbreviations: NPY, Neuropeptide Y; AS, Atherosclerosis; ECs, Endothelial cells; EC, Endothelial cell; TXA2, Thromboxane A2; NO, Nitric oxide; NOS, Nitric oxide synthases; eNOS, Endothelial NOS; nNOS, Neuronal NOS; iNOS, Inducible NOS; TF, Tissue factor; VEGF, Vascular endothelial growth factor; nAChR, Nicotinic acetylcholinergic receptors; NA, Norepinephrine; ROS, Reactive oxygen species. together lead to EC energy metabolism disruption. Besides increasing vascular tension to change the inner radius of the vessel, nicotine increases blood viscosity by increasing the quantity of plasma components such as inflammatory factors, leukocyte, and coagulation factor. Both the viscosity of blood and the inner radius of vessel can change the magnitude of shear stress, resulting in disturbed flow that induces endothelial dysfunction $(11,12)$. In essence, nicotine is detrimental to overall endothelial function.

\section{NPY AND RECEPTORS}

The 36-amino-acid polypeptide NPY, belongs to the same neuroendocrine peptide NPY family as the pancreatic polypeptide and peptide YY. NPY plays an important role in appetite, anxiety state, angiogenesis, and vasoconstriction, and is widely distributed in the central and peripheral nervous systems, especially in the hypothalamus (13). The NPY-Y receptor system belongs to the G-protein-coupled receptor superfamily; there are at least four receptors in most mammals, namely, Y1, Y2, Y4, and Y5 receptors, which have different affinity and selectivity $(14,15)$. Although NPY is mainly secreted by sympathetic nerve cells and pheochromaffin cells, it is also present in peripheral nerve terminals, peripheral fat cells, platelets, liver, and ECs (16). Central NPY can be jointly released into the peripheral circulation (17), and is associated with food intake $(18,19)$ and mood regulation $(20)$. For example, NPY induces an anxiety state through Y2R but alleviates anxiety by binding to Y1R $(21,22)$. The central NPY system is also closely associated with cardiovascular regulation. NPY has notably emerged as an important transmitter that can bind to different receptors, promote thrombosis, constrict blood vessels, and regulate insulin secretion $(23,24)$. The characteristics of NPY receptors are summarized in Table 1.

\section{NPY AND ENDOTHELIAL FUNCTION}

At least three receptors have been identified on ECs, namely, Y1R, Y2R, and Y5R (Figure 1). NPY at the physiological concentrations of eNOS and VEGF, stimulated endothelial cell proliferation, germination, migration, and adhesion, and induced ischemic angiogenesis and intimal thickening (43, $45)$, by binding to Y1R, Y2R, and Y5R $(25,46,47)$. In AS, abnormal neovascularization in plaques not only accelerates plaque progression but also increases the risk of plaque rupture and hemorrhage (48). Vasoconstriction and the discontinuity of ECs might be caused by Y1R activation within the cardiovascular system (49). Comparably, Y1R on macrophages is involved in the inflammatory response, which may contribute to endothelial dysfunction (50). Additionally, Y1R on ECs has a role in the induction of thrombosis. Sympathetic excitement may be associated with the platelet activation state. Endothelial damage stimulates NPY secretion, which induces TXA2 release, and NPY binds to Y1R on ECs, thereby promoting platelet aggregation $(41,51)$. NPY is a powerful orexin that plays a crucial role in fat storage (33) and is the main source of blood lipids. NPY not only 
TABLE 1 | Characteristics of NPY receptors.

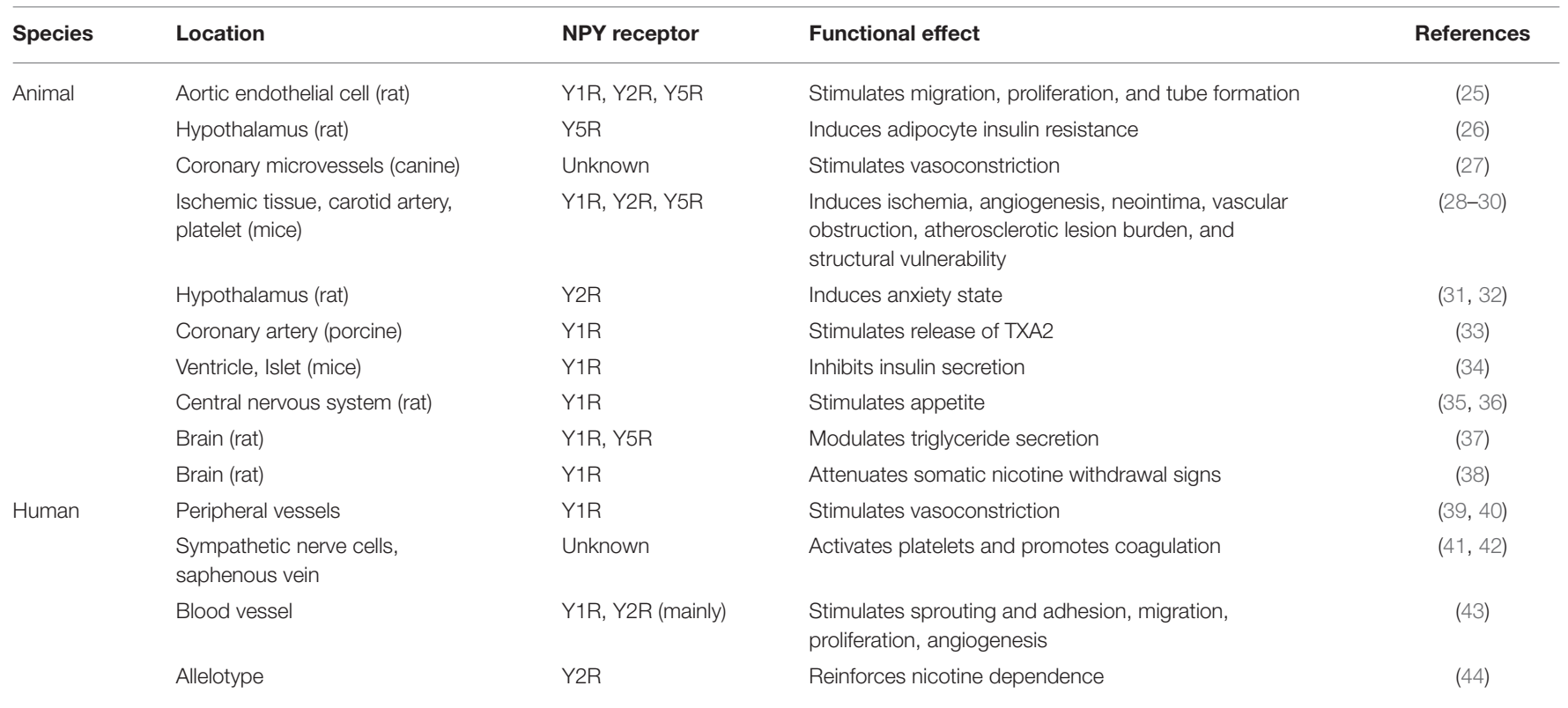

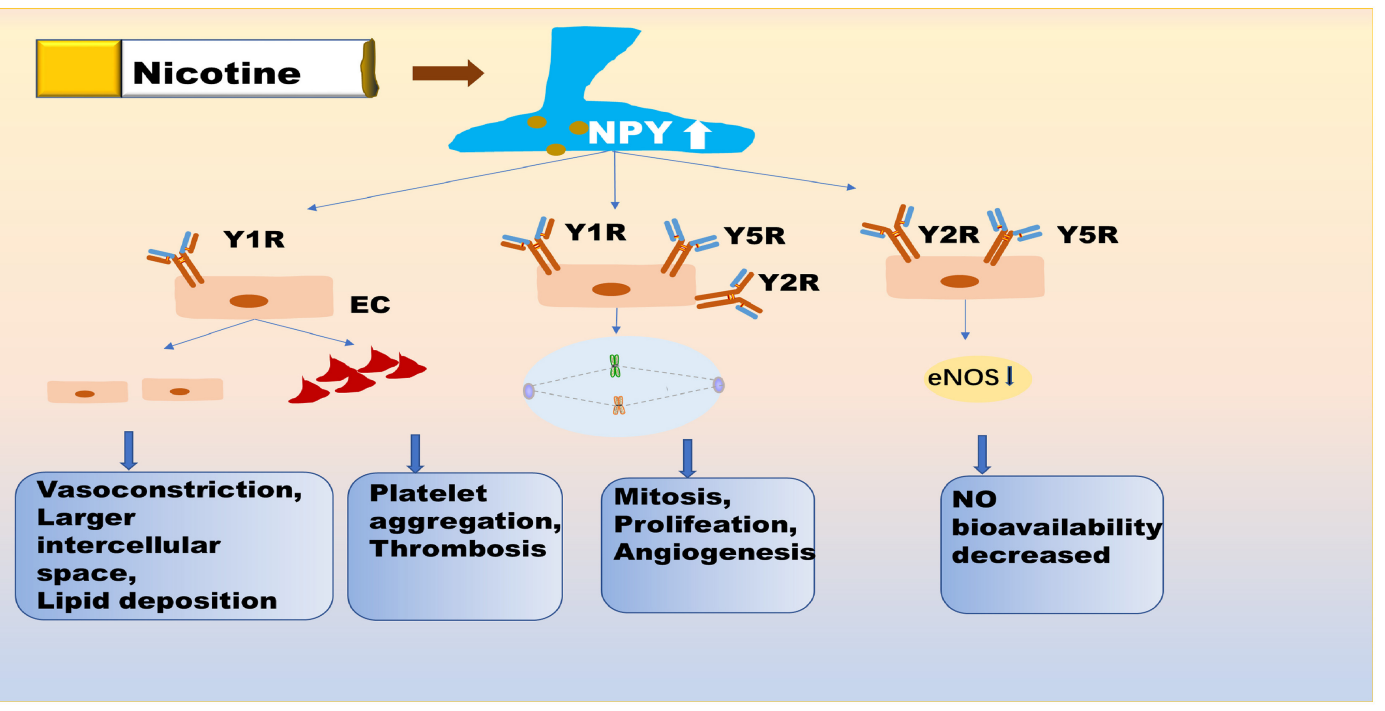

FIGURE 1 | NPY is directly involved in nicotine-induced endothelial dysfunction. Nicotine exposure promotes the expression of NPY in central and peripheral neuronal pathways. NPY not only promotes vasoconstriction and increases intercellular space, resulting in the deposition of lipid in the intima, but it also promotes platelet aggregation and thrombosis via Y1R on EC. NPY further affects the mitotic process, endothelial cell proliferation, and angiogenesis, primarily by binding to Y1R, Y2R, and Y5R. NPY also reduces the secretion of eNOS from endothelial cells, by binding to Y2R and Y5R. Y5R plays the role of enhancer for Y1R and Y2R. These pathological processes affect the normal function of endothelial cells. NPY, neuropeptide Y; Y1R/Y2R/Y5R, Y1/Y2/Y5 receptor; eNOS, endothelial nitric oxide synthase; EC, endothelial cell.

modulates insulin secretion $(35,52)$, but substantially induces insulin resistance in hepatocytes and adipocytes through Y1R and Y5R $(26,53,54)$. Endothelial dysfunction induced by NPY may be reduced NO bioavailability, partly due to Y2R-induced anxiety $(55,56)$. The Y2R also calibrates peripheral NA secretion (57). Compared to other NPY receptors, the role of Y5R is unclear. A recent study reports that $Y 5 R$ activity potentiates the function of Y1R and Y2R to promote endothelial cell proliferation (58).

\section{NPY AND NICOTINE-INDUCED ENDOTHELIAL DYSFUNCTION}

Nicotine is widely believed to be involved in various pathophysiological processes that induce endothelial dysfunction in a dose and time-dependent manner, such as promoting vasoconstriction, inducing insulin resistance, stimulating oxidative stress, and disrupting anticoagulant and procoagulant 


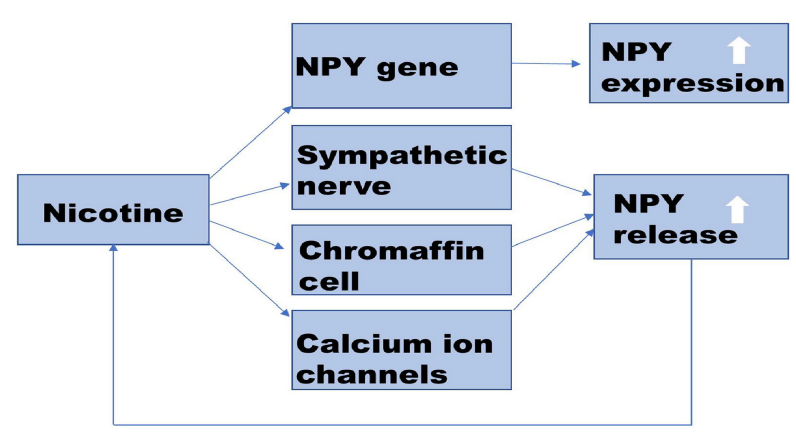

FIGURE 2 | Potential mechanism of nicotine-promoting NPY expression. Nicotine promotes the synthesis and release of NPY. In the central nervous system, nicotine up-regulates the expression of the NPY gene. In the peripheral nervous system, nicotine promotes NPY release by stimulating nAChR on sympathetic nerve and chromaffin cells. Nicotine also can activate calcium channels on the cell membrane and promote the co-release of NPY with NA. Increased NPY can affect nicotine intake. NPY, Neuropeptide Y; $\mathrm{nAChR}$, nicotinic acetylcholinergic receptor; NA, norepinephrine.

systems. Administering nicotine during postnatal days 1-8 upregulates mRNA expression of NPY in the hypothalamus of neonatal rat pups (59). In the central, nicotine promotes the expression of NPY in the hypothalamus by up-regulating the NPY gene in the rat. In the peripheral, nicotine probably promotes the release of NPY from the rat heart and adrenal gland by regulating calcium channels. Besides, nicotine can promote the co-release of NPY and NA, by directly stimulating the sympathetic nerve, as is shown in Figure 2. Similar to its effects in animals, nicotine also increased the release of NPY in human adrenal chromaffin cells (60-62). Table 2 shows that nicotine promotes NPY expression, which in turn induces endothelial dysfunction. Herein, we critically reviewed the relationship between nicotine and the NPY system to provide a broad understanding of the pathophysiological mechanisms of nicotine-induced endothelial dysfunction, especially in AS (Figure 3).

\section{NPY, Nicotine, and Vasoconstriction}

It is generally accepted that nicotine enhances vasoconstriction by disrupting the balance between vasoconstrictors (such as NA) and vasodilators (such as NO), especially in coronary arteries with endothelial damage (63). As demonstrated, nicotine elevates the level of plasma NPY, both NPY and NA are powerful vasoconstrictors (64-67). There seems to be a consensus that NPY and NA are stored together in presynaptic vesicles and in large, dense-core vesicles. In addition, NPY and NA appear to be released together, although there is no conclusive evidence describing this phenomenon (68). Low concentrations of NPY directly affect vasoconstrictors in coronary arterial microvessels (69). Electrically evoking NPY release from the perivascular nerve terminals of breast vascular and radial artery biopsies showed that NPY performed synergistically with NA to modulate vascular tone and potentiated NA-mediated vasoconstriction (27, 39). This phenomenon may be precipitated by changes in NA levels mediated by NPY-induced sympathetic excitation $(70,71)$.
TABLE 2 | Relationship between NPY and nicotine.

\begin{tabular}{|c|c|c|c|}
\hline $\begin{array}{l}\text { Nicotine } \\
\text { administration }\end{array}$ & Location & Role & References \\
\hline 4 mg/kg/days, $14 \mathrm{~d}$ & $\begin{array}{l}\text { Hypothalamus } \\
\text { (rat) }\end{array}$ & $\begin{array}{l}\text { Enhances NPY } \\
\text { expression and } \\
\text { promotes food intake }\end{array}$ & (2) \\
\hline $6 \mathrm{mg} / \mathrm{kg} /$ days, $14 \mathrm{~d}$ & $\begin{array}{l}\text { Hypothalamus } \\
\text { (adult rat } \\
\text { progeny) }\end{array}$ & $\begin{array}{l}\text { Changes hypothalamic } \\
\text { neuropeptides in the } \\
\text { adult progeny }\end{array}$ & (3) \\
\hline $10 \mu \mathrm{mM} / \mathrm{l}, 10 \mathrm{~min}$ & $\begin{array}{l}\text { Coronary venous } \\
\text { (guinea pig) }\end{array}$ & $\begin{array}{l}\text { Induces NA release and } \\
\text { promotes NPY overflow }\end{array}$ & (4) \\
\hline $\begin{array}{l}0.25,1.5 \text {, and } 3 \mathrm{mg} / \mathrm{kg} \text {, } \\
\text { twice daily, } 8 \text { days }\end{array}$ & $\begin{array}{l}\text { Arcuate nucleus } \\
\text { (neonatal rat } \\
\text { pups) }\end{array}$ & $\begin{array}{l}\text { Increases expression of } \\
\text { NPY }\end{array}$ & (60) \\
\hline $100 \mu \mathrm{M}, 10 \mathrm{~min}$ & $\begin{array}{l}\text { Adrenal } \\
\text { chromaffin cells } \\
\text { (human) }\end{array}$ & $\begin{array}{l}\text { Elicits a rapid increase } \\
\text { in the release of NPY }\end{array}$ & (62) \\
\hline $5 \mathrm{mg} / \mathrm{kg}, 6 \mathrm{~h}$ & Adrenal (rat) & $\begin{array}{l}\text { Upregulates } \\
\text { neuropeptide synthesis }\end{array}$ & (63) \\
\hline
\end{tabular}

In particular, NPY-induced TXA2 release may have a strong effect on NA-mediated vasoconstriction, further confirmed by studies inhibiting NPY spontaneous vasoconstriction with TXA2 synthase inhibitors (72). NPY evokes potent, long-lasting vasoconstriction by binding to Y1R on ECs and smooth muscle cells $(40,42)$ induced by sympathetic stimulation, but not NA (73). Long-term incubation with NPY decreases the expression of eNOS mRNA and eNOS protein levels in human umbilical vein endothelial cells (74). There is correlation between gender and NPY-induced vasoconstriction; the latter is reduced in the presence of female sex hormones (75). Therefore, we speculate that nicotine-induced elevated NPY disrupts the bioavailability of NO. Nicotine induces several cardiovascular effects, from increasing myocardial contractility and blood pressure to increasing cardiac load and blood flow resistance. The potential mechanism for this is nicotine stimulating the release of NPY and NA by activating $\mathrm{nAChR}$ localized on peripheral postganglionic sympathetic nerve endings and the adrenal medulla.

\section{NPY, Nicotine, and Angiogenesis}

Angiogenesis is a vital pathophysiological process that includes the proliferation and migration of ECs and it is regulated by a series of stimuli (76-78). Indeed, abnormal angiogenesis can induce or augment pathological conditions. Nicotine plays a substantial role in the proliferation of vascular ECs and in pathological angiogenesis in ischemia $(79,80)$. Analogous to the effects of nicotine, NPY can promote EC proliferation and angiogenesis in atherosclerotic arteries $(28,81)$, which can increase the risk of AS. Platelet NPY stimulates EC mitosis through Y1R, and stimulates EC proliferation through Y2R and $\mathrm{Y} 5 \mathrm{R}$, thereby promoting plaque neovascularization (82). Besides, plaque neovascularization notably destabilizes plaque and increases risk of bleeding. Intimal thickening and plaque formation induced by nicotine leads to disturbances in blood flow patterns, with lowered net forward flow and shear stress. In contrast, NPY increases risk of re-infarction after angioplasty, and is an important contributor to ischemic tissue after 


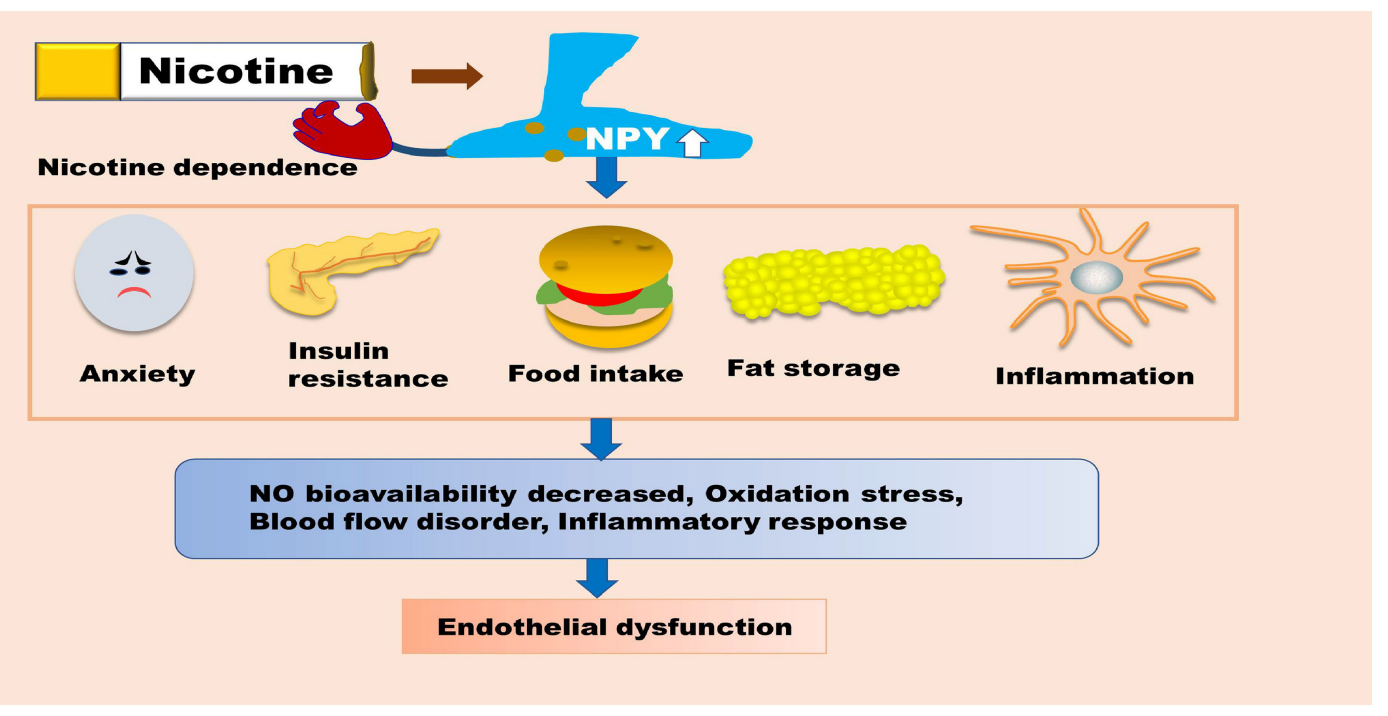

FIGURE 3 | NPY is indirectly involved in nicotine-induced endothelial dysfunction. NPY can promote insulin resistance, food intake, and fat storage, as well as enhance macrophage-mediated inflammatory responses. NPY can also increase the body's dependence on nicotine, which indirectly aggravates endothelial dysfunction. These pathological processes can promote oxidative stress, inflammatory responses, blood flow disorders, and reduce the bioavailability of NO, ultimately inducing endothelial dysfunction. NPY, Neuropeptide Y; NO, nitric oxide.

angioplasty, as it promotes neointima, thrombosis, and vascular obstruction by activating Y1R and Y5R (29). Furthermore, Y1 and Y5 receptor inhibitors can reduce these pathological processes and suggest a potential target for the treatment and prevention of vascular plasticization-related complications (83). NPY increases angiogenesis and arteriogenesis, but does not increase blood flow to the ischemic myocardium (30). Therefore, we speculate that NPY directly correlates with nicotine-induced pathological EC proliferation and angiogenesis. However, the specific mechanism needs further study. Nicotine affects the secretion function of ECs, leading to platelet adhesion and aggregation, by increasing TF and TXA2 expression, reducing prostaglandin I-2 expression, and NPY combined with those to promote thrombosis. NPY not only directly stimulates vasoconstriction associated with platelet aggregation to promote thrombosis $(84,85)$, but also induces anxiety $(31,86)$, which contributes substantially to platelet activation (32) by activating $\mathrm{Y} 2 \mathrm{R}$ in the hypothalamus and striatum. Therefore, nicotine and NPY play a combined role in promoting pathological angiogenesis and thrombosis.

\section{NPY, Nicotine, and Energy Metabolism}

Smoking has been well-established as an independent risk factor for AS. Nicotine exposure can cause a variety of pathological effects on ECs, among which the disturbance of energy metabolisms of ECs is particularly destructive (87). Chronic nicotine consumption promotes the expression of NPY (88), which is involved in the regulation of energy metabolism (36, 89-91), and shows a gender-dependent difference in the hypothalamus (92). NPY is a powerful appetite peptide (93, 94). Elevated NPY levels in the hypothalamic arcuate nucleus lead to hyperphagia and significant body weight gain. It is also known that excess energy can result in hyperlipidemia and hyperglycemia, the latter of which can directly destroy protein structures, damaging blood vessels. Hyperlipidemia and hyperglycemia can both increase the production of inflammatory cytokines, which can prompt foam cell formation and induce endothelial dysfunction. However, nicotine can inhibit weight gain by increasing leptin expression in the hypothalamus of food-deprived rats (95). Evidence supports the notion that NPY plays an important role in inhibiting insulin secretion, causing hyperglycemia in mice (96). NPY binding to Y1R on islet cells induces insulin resistance and enhances beta-cell replication by regulating the extracellular signal activity (34). Moreover, hyperglycemia, caused by insulin resistance and abnormal insulin secretion, can lead to ROS accumulation and decreased NO bioavailability, thus promoting endothelial dysfunction (97-100).

\section{NPY, Nicotine, and Oxidative Stress}

Nicotine is a powerful oxidant that increases ROS production in plasma and induces leukocyte adhesion. Both of these effects, if left uncontrolled, will lead to expanded intercellular space of ECs and endothelial dysfunction (101). Furthermore, nicotine not only destroys lipid homeostasis but also oxidizes blood lipids to lipoproteins of different densities via ROS, thus promoting leukocyte phagocytosis of lipoproteins and forming foam cells, which is the key pathogenesis of AS $(102,103)$. NPY promotes the storage of fats such as triglycerides and cholesterol and increases the source of lipoproteins, leading to oxidative stress and endothelial dysfunction (104). NPY and endothelial dysfunction can reinforce each other. Endothelial dysfunction can stimulate the secretion of NPY and promote leukocyte chemotaxis, thus expanding vascular inflammation (37, 105107). NPY also directly regulates inflammation in human ECs 
$(108,109)$. In addition, inflammation stress plays a role in obesity-related cognitive impairment $(110,111)$. Lipid deposition induced by NPY and an increase in oxidative substances induced by nicotine can not only increase blood viscosity, but also promote the formation of lipid strips in AS.

\section{NPY and Nicotine Dependence}

Nicotine addiction is a chronic disorder characterized by dysphoria upon nicotine withdrawal and relapse after periods of abstinence. Withdrawal and relapse increase levels of NPY and its receptor proteins in the central nervous system, especially the Y1 receptor associated with brain reward function (112). NPY and Y1R agonists improve pathological withdrawal signs and negative affective states (113). Conversely, increased Y2R expression in the hippocampal CA3 region might play an important role in nicotine withdrawal-induced social dysfunction behavior and is involved in the mediation of nicotine relapse (38). Importantly, manipulations of $\mathrm{Y} 1 \mathrm{R}$ and $\mathrm{Y} 2 \mathrm{R}$ signals can regulate nicotine usage and $\mathrm{Y} 1 \mathrm{R}$ agonists and $\mathrm{Y} 2 \mathrm{R}$ antagonists promote reduced nicotine intake in central system regions $(114,115)$. In addition, upon investigating 2517 Japanese elderly smokers, it was discovered that the prevalence of the NPY2R rs $4425326 \mathrm{C}$ allele and the rs4425326 homozygous $\mathrm{T}$ allelotype was obviously associated with nicotine dependence (116). Thus, NPY can affect nicotine consumption, and is a promising target for treating nicotine-induced endothelial dysfunction.

In conclusion, nicotine can regulate the expression of NPY, which can affect human nicotine intake. NPY may play a role as an enhancer in nicotine-induced endothelial dysfunction. Nicotine can cause changes in damage to the vascular wall, initiation of atherogenesis, hemorheological parameters, and coronary artery hemodynamics. NPY can increase blood flow resistance by promoting not only vasoconstriction but also platelet aggregation and vascular plaque formation. NPY can also promote lipid deposition, inflammatory reaction, and leukocyte adhesion, resulting in a hypercoagulable blood state. As such, NPY aggravates blood flow disorder induced by nicotine. The flow disordered can further induce endothelial dysfunction.

\section{CONCLUSIONS AND FUTURE DIRECTIONS}

The role of NPY polymorphism in the regulation of cardiovascular activity has been studied, but the effect on endothelial function has varied in different studies, possibly due to varied receptor effects. Few studies have explored the regulation of NPY in vascular endothelial dysfunction and AS. Lagraauw et al. observed that focalized NPY overexpression in the carotid artery significantly increased atherosclerotic plaque size and perivascular mast cell activity in apoE(-/-) mice. NPY

\section{REFERENCES}

1. Puranik R, Celermajer D. Smoking and endothelial function. Progress Cardiovasc Dis. (2003) 45:443-58. doi: 10.1053/pcad.2003.YPCAD13 may impact plaque progression in part via mast cell activation (28). In particular, the role of NPY in vascular endothelial dysfunction in smokers remains unclear. Polymorphisms of the NPY gene determine its functional complexity, reflected in its ability to induce angiogenesis and vascular remodeling. NPY improved functional blood flow in mice with hind limb ischemia (44), but has also contributed to the development of AS by promoting thrombosis and oxidative stress blood vessels (117). The discovery and complete utilization of NPY functions, including the promotion of EC proliferation and NO secretion, may direct future research and generate hope for the clinical treatment of arteriosclerotic cardiovascular disease. Evidence suggests that an excited sympathetic nervous system induced by an acute coronary heart attack, can promote NPY release, thereby causing coronary artery spasm and aggravating further myocardial ischemia. However, additional in vitro and in vivo experimental studies are urgently needed to further support these findings. NPY led to neointima formation, and triggered thrombosis and vessel occlusion. Therefore, NPY receptor antagonists may offer a new approach to treating restenosis. NPY demonstrated an important role in stem cell therapy for acute myocardial infarction, by regulating vascular access for progenitor cells (118), as well as defended the nerves of bone marrow $(119,120)$. NPY diversity determines the complexity of its functions. NPY can promote cell proliferation, increasing the risk of coronary heart disease reinfarction and rebleeding. Smoking can affect the expression of NPY, which can aggravate endothelial dysfunction and blood flow disorder induced by nicotine. In light of this, NPY receptor-targeted therapy may be useful in treating nicotine-related cardiovascular diseases. At present, research on NPY is mostly limited to animal experiments; therefore, more human experiments are needed to further confirm the function and mechanism of NPY. A thorough study on the relationship between NPY and coronary heart disease may open the door for new treatments for the latter. Moreover, the prevention and treatment of nicotinerelated cardiovascular diseases present a major challenge for providing medical care.

\section{AUTHOR CONTRIBUTIONS}

Y-lZ helped to draft the manuscript and prepare tables and figures. $\mathrm{W}$-dW and $\mathrm{M}-\mathrm{mL}$ contributed to an extensive literature review. H-lL and SL provided the subject of the review, critically revised, and edited the manuscript. All authors have read and approved the final version of the manuscript, and agreed with the order in which the authors are presented.

\section{FUNDING}

This work was supported by 2018C053R.

2. Li MD, Kane JK, Parker SL, McAllen K, Matta SG, Sharp BM. Nicotine administration enhances NPY expression in the rat hypothalamus. Brain Res. (2000) 867:157-64. doi: 10.1016/s0006-8993(00)0 2283-6 
3. Younes-Rapozo V, Moura EG, Manhaes AC, Pinheiro CR, Santos-Silva AP, de Oliveira E, et al. Maternal nicotine exposure during lactation alters hypothalamic neuropeptides expression in the adult rat progeny. Food Chem Toxicol. (2013) 58:158-68. doi: 10.1016/j.fct.2013.04.036

4. Richardt G, Brenn T, Seyfarth M, Haass M, Schömig E, Schömig A. Dual effect of nicotine on cardiac noradrenaline release during metabolic blockade. Basic Res Cardiol. (1994) 89:524-34. doi: 10.1007/bf00794952

5. Gao B, Li L, Zhu PF, Zhang MJ, Hou LB, Sun YF, et al. Chronic administration of methamphetamine promotes atherosclerosis formation in ApoE-/- knockout mice fed normal diet. Atherosclerosis. (2015) 243:26877. doi: 10.1016/j.atherosclerosis.2015.09.001

6. Cracowski JL, Roustit M. Human skin microcirculation. Compreh Physiol. (2020) 10:1105-54. doi: 10.1002/cphy.c190008

7. Magierowska K, Wojcik D, Chmura A, Bakalarz D, Wierdak M, Kwiecien $\mathrm{S}$, et al. Alterations in gastric mucosal expression of calcitonin generelated peptides, vanilloid receptors, and heme oxygenase-1 mediate gastroprotective action of carbon monoxide against ethanol-induced gastric mucosal lesions. Int J Mol Sci. (2018) 19:2960. doi: 10.3390/ijms19102960

8. Cardinale A, Nastrucci C, Cesario A, Russo P. Nicotine: specific role in angiogenesis, proliferation and apoptosis. Crit Rev Toxicol. (2012) 42:6889. doi: $10.3109 / 10408444.2011 .623150$

9. Lee J, Cooke J. Nicotine and pathological angiogenesis. Life Sci. (2012) 91:1058-64. doi: 10.1016/j.lfs.2012.06.032

10. Toda N, Okamura T. Cigarette smoking impairs nitric oxidemediated cerebral blood flow increase: implications for Alzheimer's disease. J Pharmacol Sci. (2016) 131:223-32. doi: 10.1016/j.jphs.2016. 07.001

11. Haustein K, Krause J, Haustein H, Rasmussen T, Cort N. Effects of cigarette smoking or nicotine replacement on cardiovascular risk factors and parameters of haemorheology. J. Intern. Med. (2002) 252:130-9. doi: 10.1046/j.1365-2796.2002.01014.x

12. Chiu J, Chien S. Effects of disturbed flow on vascular endothelium: pathophysiological basis and clinical perspectives. Physiol Rev. (2011) 91:327-87. doi: 10.1152/physrev.00047.2009

13. Aveleira C, Botelho M, Cavadas C. NPY/neuropeptide Y enhances autophagy in the hypothalamus: a mechanism to delay aging? Autophagy. (2015) 11:1431-3. doi: 10.1080/15548627.2015.1062202

14. Peng S, Zhou Y, Song Z, Lin S. Effects of neuropeptide y on stem cells and their potential applications in disease therapy. Stem Cells Int. (2017) 2017:6823917. doi: 10.1155/2017/6823917

15. Yang Z, Han S, Keller M, Kaiser A, Bender B, Bosse M, et al. Structural basis of ligand binding modes at the neuropeptide Y Y receptor. Nature. (2018) 556:520-524. doi: 10.1038/s41586-018-0046-x

16. Businaro R, Scaccia E, Bordin A, Pagano F, Corsi M, Siciliano C, et al. Platelet lysate-derived neuropeptide $\mathrm{y}$ influences migration and angiogenesis of human adipose tissue-derived stromal cells. Sci Rep. (2018) 8:14365. doi: 10.1038/s41598-018-32623-8

17. Mormède $\mathrm{P}$, Castagné V, Rivet J, Gaillard R, Corder R. Involvement of neuropeptide $\mathrm{Y}$ in neuroendocrine stress responses. Central and peripheral studies. J Neural Transm. (1990) 29:65-75. doi: 10.1007/978-3-7091-9050-0_8

18. Comeras L, Herzog H, Tasan R. Neuropeptides at the crossroad of fear and hunger: a special focus on neuropeptide Y. Ann NY Acad Sci. (2019) 1455:59-80. doi: 10.1111/nyas.14179

19. Chen Y, Essner R, Kosar S, Miller O, Lin Y, Mesgarzadeh S, et al. Sustained NPY signaling enables AgRP neurons to drive feeding. eLife. (2019) 8:e46348. doi: 10.7554/eLife.46348

20. Cheng Y, Tang X, Li Y, Zhao D, Cao Q, Wu H, et al. Depressioninduced neuropeptide $y$ secretion promotes prostate cancer growth by recruiting myeloid cells. Clin Cancer Res. (2019) 25:2621-32. doi: 10.1158/1078-0432.Ccr-18-2912

21. Reichmann F, Holzer P. Neuropeptide Y: a stressful review. Neuropeptides. (2016) 55:99-109. doi: 10.1016/j.npep.2015.09.008

22. Hassan A, Mancano G, Kashofer K, Fröhlich E, Matak A, Mayerhofer R, et al. High-fat diet induces depression-like behaviour in mice associated with changes in microbiome, neuropeptide $\mathrm{Y}$, and brain metabolome. Nutri Neurosci. (2019) 22:877-93. doi: 10.1080/1028415x.2018.14 65713
23. Imai Y, Patel H, Hawkins E, Doliba N, Matschinsky F, Ahima R. Insulin secretion is increased in pancreatic islets of neuropeptide Y-deficient mice. Endocrinology. (2007) 148:5716-23. doi: 10.1210/en.2007-0404

24. Yu J, Loh K, Song Z, Yang H, Zhang Y, Lin S. Update on glycerol-3-phosphate acyltransferases: the roles in the development of insulin resistance. Nutrit Diab. (2018) 8:34. doi: 10.1038/s41387-018-0045-x

25. Chen Z, Feng G, Nishiwaki K, Shimada Y, Fujiwara Y, Komatsu T, et al. Possible roles of neuropeptide Y Y3-receptor subtype in rat aortic endothelial cell proliferation under hypoxia, and its specific signal transduction. Am J Physiol Heart Circul Physiol. (2007) 293:H95967. doi: 10.1152/ajpheart.00886.2006

26. Qiu J, Bosch M, Zhang C, Rønnekleiv O, Kelly M. Estradiol protects neuropeptide y/agouti-related peptide neurons against insulin resistance in females. Neuroendocrinology. (2020) 110:105-18. doi: 10.1159/000501560

27. Donoso M, Miranda R, Irarrázaval M, Huidobro-Toro J. Neuropeptide Y is released from human mammary and radial vascular biopsies and is a functional modulator of sympathetic cotransmission. J Vasc Res. (2004) 41:387-99. doi: 10.1159/000080900

28. Lagraauw H, Westra M, Bot M, Wezel A, van Santbrink P, Pasterkamp $\mathrm{G}$, et al. Vascular neuropeptide $\mathrm{Y}$ contributes to atherosclerotic plaque progression and perivascular mast cell activation. Atherosclerosis. (2014) 235:196-203. doi: 10.1016/j.atherosclerosis.2014.04.025

29. Wu W, Peng S, Shi Y, Li L, Song Z, Lin S. NPY promotes macrophage migration by upregulating matrix metalloproteinase- 8 expression. J Cell Physiol. (2020) 236:1903-12. doi: 10.1002/jcp.29973

30. Robich M, Matyal R, Chu L, Feng J, Xu S, Laham R, et al. Effects of neuropeptide $\mathrm{Y}$ on collateral development in a swine model of chronic myocardial ischemia. J Mol Cell Cardiol. (2010) 49:102230. doi: 10.1016/j.yjmcc.2010.08.022

31. Thorsell A, Slawecki C, El Khoury A, Mathe A, Ehlers C. The effects of social isolation on neuropeptide $\mathrm{Y}$ levels, exploratory and anxietyrelated behaviors in rats. Pharmacol Biochem Behav. (2006) 83:2834. doi: 10.1016/j.pbb.2005.12.005

32. Hoirisch-Clapauch S. Anxiety-related bleeding and thrombosis. Sem Thromb Hemost. (2018) 44:656-61. doi: 10.1055/s-0038-1639501

33. Rojas J, Stafford J, Saadat S, Printz R, Beck-Sickinger A, Niswender $\mathrm{K}$. Central nervous system neuropeptide $\mathrm{Y}$ signaling via the Y1 receptor partially dissociates feeding behavior from lipoprotein metabolism in lean rats. Am J Physiol Endocrinol Metab. (2012) 303:E1479-88. doi: 10.1152/ajpendo.00351.2012

34. Cho Y, Kim C. Neuropeptide Y promotes beta-cell replication via extracellular signal-regulated kinase activation. Biochem Biophys Res Commun. (2004) 314:773-80. doi: 10.1016/j.bbrc.2003.12.170

35. Kulkarni R, Wang Z, Wang R, Smith D, Ghatei M, Bloom S. Glibenclamide but not other sulphonylureas stimulates release of neuropeptide $\mathrm{Y}$ from perifused rat islets and hamster insulinoma cells. J Endocrinol. (2000) 165:509-18. doi: 10.1677/joe.0.1650509

36. Sun W, Li L, Huang X, Shi Y, Yang H, Song Z, et al. The central mechanism of risperidone-induced hyperprolactinemia. Progress Neuro-Psychopharm Biol Psychiatry. (2017) 76:134-9. doi: 10.1016/j.pnpbp.2017.03.009

37. Choi B, Shin M, Kim E, Park J, Lee H, Kim S, et al. Elevated neuropeptide $\mathrm{y}$ in endothelial dysfunction promotes macrophage infiltration and smooth muscle foam cell formation. Front Immunol. (2019) 10:1701. doi: 10.3389/fimmu.2019.01701

38. Aydin C, Oztan O, Isgor C. Vulnerability to nicotine abstinence-related social anxiety-like behavior: molecular correlates in neuropeptide Y, Y2 receptor and corticotropin releasing factor. Neurosci Lett. (2011) 490:220 5. doi: 10.1016/j.neulet.2010.12.056

39. Dietrich P, Moleda L, Kees F, Müller M, Straub R, Hellerbrand C, et al. Dysbalance in sympathetic neurotransmitter release and action in cirrhotic rats: impact of exogenous neuropeptide Y. J Hepatol. (2013) 58:25461. doi: 10.1016/j.jhep.2012.09.027

40. Lundberg J, Franco-Cereceda A, Hemsén A, Lacroix J, Pernow J. Pharmacology of noradrenaline and neuropeptide tyrosine (NPY)mediated sympathetic cotransmission. Fund Clin Pharm. (1990) 4:373-91. doi: 10.1111/j.1472-8206.1990.tb00692.x

41. Tsurumaki T, Nagai S, Bo X, Toyosato A, Higuchi H. Potentiation by neuropeptide $\mathrm{Y}$ of $5 \mathrm{HT} 2 \mathrm{~A}$ receptor-mediated contraction 
in porcine coronary artery. Europ J Pharm. (2006) 544:1117. doi: 10.1016/j.ejphar.2006.06.036

42. Hubers S, Wilson J, Yu C, Nian H, Grouzmann E, Eugster P, et al. DPP (Dipeptidyl Peptidase)-4 inhibition potentiates the vasoconstrictor response to NPY (Neuropeptide Y) in humans during reninangiotensin-aldosterone system inhibition. Hypertension. (2018) 72:712-9. doi: 10.1161/hypertensionaha.118.11498

43. Movafagh S, Hobson J, Spiegel S, Kleinman H, Zukowska Z. Neuropeptide $\mathrm{Y}$ induces migration, proliferation, and tube formation of endothelial cells bimodally via Y1, Y2, and Y5 receptors. FASEB J. (2006) 20:19246. doi: 10.1096/fj.05-4770fje

44. Eshun D, Saraf R, Bae S, Jeganathan J, Mahmood F, Dilmen S, et al. Neuropeptide Y incorporated into PVAX nanoparticle improves functional blood flow in a murine model of hind limb ischemia. J Appl Physiol. (2017) 122:1388-97. doi: 10.1152/japplphysiol.00467.2016

45. Zukowska-Grojec Z, Karwatowska-Prokopczuk E, Rose W, Rone J, Movafagh S, Ji H, et al. Neuropeptide Y: a novel angiogenic factor from the sympathetic nerves and endothelium. Circul Res. (1998) 83:18795. doi: 10.1161/01.res.83.2.187

46. Ribatti D, Conconi M, Nussdorfer G. Nonclassic endogenous novel [corrected] regulators of angiogenesis. Pharmacol Rev. (2007) 59:185205. doi: $10.1124 /$ pr.59.2.3

47. Klinjampa R, Sitticharoon C, Souvannavong-Vilivong X, Sripong C, Keadkraichaiwat I, Churintaraphan $\mathrm{M}$, et al. Placental Neuropeptide Y (NPY) and NPY receptors expressions and serum NPY levels in preeclampsia. Exp Biol Med. (2019) 244:380-8. doi: 10.1177/1535370219831437

48. Zhu P, Sun W, Zhang C, Song Z, Lin S. The role of neuropeptide Y in the pathophysiology of atherosclerotic cardiovascular disease. Int J Cardiol. (2016) 220:235-41. doi: 10.1016/j.ijcard.2016.06.138

49. Grundemar L, Håkanson R. Neuropeptide Y effector systems: perspectives for drug development. Trends Pharm Sci. (1994) 15:153-9. doi: 10.1016/0165-6147(94)90076-0

50. Zhou J, Zhang L, Wei H, Wang X, Ni H, Yang F, et al. Neuropeptide $\mathrm{Y}$ induces secretion of high-mobility group box 1 protein in mouse macrophage via PKC/ERK dependent pathway. J Neuroimmunol. (2013) 260:55-9. doi: 10.1016/j.jneuroim.2013.04.005

51. Zaldivia M, Hering D, Marusic P, Sata Y, Lee R, Esler M, et al. Successful renal denervation decreases the platelet activation status in hypertensive patients. Cardiovasc Res. (2020) 116:202-10. doi: 10.1093/cvr/cvz033

52. Xue J, Scotti E, Stoffel M. CDK8 regulates insulin secretion and mediates postnatal and stress-induced expression of neuropeptides in pancreatic $\beta$ cells. Cell Rep. (2019) 28:2892-904.e7. doi: 10.1016/j.celrep.2019. 08.025

53. Long M, Zhou J, Li D, Zheng L, Xu Z, Zhou S. Long-term over-expression of neuropeptide $\mathrm{y}$ in hypothalamic paraventricular nucleus contributes to adipose tissue insulin resistance partly via the Y5 receptor. PLOS ONE. (2015) 10:e0126714. doi: 10.1371/journal.pone.0126714

54. Gomes R, Bueno F, Schamber C, de Mello J, de Oliveira J, Francisco F, et al. Maternal diet-induced obesity during suckling period programs offspring obese phenotype and hypothalamic leptin/insulin resistance. J Nutr Biochem. (2018) 61:24-32. doi: 10.1016/j.jnutbio.2018.07.006

55. Ritz T, Trueba A. Airway nitric oxide and psychological processes in asthma and health: a review. Ann Allergy Asthma Immunol. (2014) 112:3028. doi: 10.1016/j.anai.2013.11.022

56. Yue $\mathrm{Y}, \mathrm{Xu} \mathrm{D}$, Wang $\mathrm{Y}$, Wang $\mathrm{X}$, Xia $\mathrm{F}$. Effect of inducible nitric oxide synthase and neuropeptide $\mathrm{Y}$ in plasma and placentas from intrahepatic cholestasis of pregnancy. J Obstetr Gynaecol Res. (2018) 44:1377-383. doi: $10.1111 /$ jog.13681

57. Zukowska Z, Pons J, Lee E, Li L. Neuropeptide Y: a new mediator linking sympathetic nerves, blood vessels and immune system? Can J Physiol Pharmacol. (2003) 81:89-94. doi: 10.1139/y03-006

58. Tan C, Green P, Tapoulal N, Lewandowski A, Leeson P, Herring N. The role of neuropeptide $\mathrm{Y}$ in cardiovascular health and disease. Front Physiol. (2018) 9:1281. doi: 10.3389/fphys.2018.01281

59. Huang L, Winzer-Serhan U. Nicotine regulates mRNA expression of feeding peptides in the arcuate nucleus in neonatal rat pups. Dev Neurob. (2007) 67:363-77. doi: $10.1002 /$ dneu.20348
60. Hiremagalur B, Sabban E. Nicotine elicits changes in expression of adrenal catecholamine biosynthetic enzymes, neuropeptide $Y$ and immediate early genes by injection but not continuous administration. Brain Res Molecular Brain Res. (1995) 32:109-5. doi: 10.1016/0169-328x(95)0 0068-4

61. Cavadas C, Silva A, Mosimann F, Cotrim M, Ribeiro C, Brunner H, et al. NPY regulates catecholamine secretion from human adrenal chromaffin cells. $J$ Clin Endocrinol Metab. (2001) 86:5956-63. doi: 10.1210/jcem.86.12.8091

62. Jahng J, Houpt T, Joh T, Wessel T. Expression of catecholaminesynthesizing enzymes, peptidylglycine alpha-amidating monooxygenase, and neuropeptide $\mathrm{Y}$ mRNA in the rat adrenal medulla after acute systemic nicotine. J Mol Neurosci. (1997) 8:45-52. doi: 10.1007/bf02736862

63. De Sousa P, Cherian G, Thomas J, Thulesius O. Coronary artery constriction is enhanced with nicotine and propranolol, particularly after endothelial damage. Clin Physiol. (1991) 11:143-52. doi: 10.1111/j.1475-097x.1991.tb00107.x

64. Herring N, Tapoulal N, Kalla M, Ye X, Borysova L, Lee R, et al. Neuropeptide$\mathrm{Y}$ causes coronary microvascular constriction and is associated with reduced ejection fraction following ST-elevation myocardial infarction. Europ Heart J. (2019) 40:1920-29. doi: 10.1093/eurheartj/ehz115

65. Prieto D, Arcos L, Martínez P, Benedito S, García-Sacristán A, Hernández M. Heterogeneity of the neuropeptide Y (NPY) contractile and relaxing receptors in horse penile small arteries. Br J Pharmacol. (2004) 143:97686. doi: $10.1038 /$ sj.bjp. 0706005

66. Mirman B, Ikeda I, Zhang Z, Liu Y, Yu L, Ehsan A, et al. Effects of neuropeptide $\mathrm{Y}$ on the microvasculature of human skeletal muscle. Surgery. (2020) 168:155-9. doi: 10.1016/j.surg.2020.04.020

67. Pedrazzini T, Pralong F, Grouzmann E. Neuropeptide Y: the universal soldier. CMLS. (2003) 60:350-77. doi: 10.1007/s000180300029

68. Pablo Huidobro-Toro J, Verónica Donoso M. Sympathetic co-transmission: the coordinated action of ATP and noradrenaline and their modulation by neuropeptide $\mathrm{Y}$ in human vascular neuroeffector junctions. Europ J Pharm. (2004) 500:27-35. doi: 10.1016/j.ejphar.2004.07.008

69. Komaru T, Ashikawa K, Kanatsuka H, Sekiguchi N, Suzuki T, Takishima T. Neuropeptide $\mathrm{Y}$ modulates vasoconstriction in coronary microvessels in the beating canine heart. Circul Res. (1990) 67:1142-51. doi: 10.1161/01.res.67.5.1142

70. Woo N, Ganguly P. Altered neuropeptide Y effects on noradrenaline levels in the paraventricular nucleus of rats following aortic constriction. Can J Cardiol. (1994) 10:471-6.

71. Calvillo L, Gironacci M, Crotti L, Meroni P, Parati G. Neuroimmune crosstalk in the pathophysiology of hypertension. Nat Rev Cardiol. (2019) 16:476-90. doi: 10.1038/s41569-019-0178-1

72. Fabi F, Argiolas L, Ruvolo G, del Basso P. Neuropeptide Y-induced potentiation of noradrenergic vasoconstriction in the human saphenous vein: involvement of endothelium generated thromboxane. $\mathrm{Br} J$ Pharm. (1998) 124:101. doi: 10.1038/sj.bjp.0701808

73. Stephens D, Saad A, Bennett L, Kosiba W, Johnson J. Neuropeptide $Y$ antagonism reduces reflex cutaneous vasoconstriction in humans. Am J Physiol Heart Circul Physiol. (2004) 287:H14049. doi: 10.1152/ajpheart.00061.2004

74. Kaipio K, Vahlberg T, Suominen M, Pesonen U. The role of non-synonymous NPY gene polymorphism in the nitric oxide production in HUVECs. Biochem Biophys Res Commun. (2009) 381:587-91. doi: 10.1016/j.bbrc.2009.02.094

75. Olver T, Hiemstra J, Edwards J, Schachtman T, Heesch C, Fadel P, et al. Loss of female sex hormones exacerbates cerebrovascular and cognitive dysfunction in aortic banded miniswine through a neuropeptide Y-Caactivated potassium channel-nitric oxide mediated mechanism. J Am Heart Assoc. (2017) 6:e007409. doi: 10.1161/jaha.117.007409

76. Sajib S, Zahra F, Lionakis M, German N, Mikelis C. Mechanisms of angiogenesis in microbe-regulated inflammatory and neoplastic conditions. Angiogenesis. (2018) 21:1-4. doi: 10.1007/s10456-017-9583-4

77. Saraf R, Mahmood F, Amir R, Matyal R. Neuropeptide $\mathrm{Y}$ is an angiogenic factor in cardiovascular regeneration. Europ J Pharm. (2016) 776:6470. doi: 10.1016/j.ejphar.2016.02.033

78. Chen X, Zhou Y, Liang S, Shi Y, Lin S, Shu M. Overexpression of UHRF1 promoted the proliferation of vascular smooth cells 
via the regulation of Geminin protein levels. Biosci Rep. (2019) 39:BSR20181341. doi: 10.1042/bsr20181341

79. Heeschen C, Weis M, Cooke J. Nicotine promotes arteriogenesis. J Am Coll Cardiol. (2003) 41:489-96. doi: 10.1016/s0735-1097(02)02818-8

80. Jiang Z, Zhou Y, Chen X, Li L, Liang S, Lin S, et al. Different effects of neuropeptide $\mathrm{Y}$ on proliferation of vascular smooth muscle cells via regulation of Geminin. Mol Cell Biochem. (2017) 433:20511. doi: 10.1007/s11010-017-3028-7

81. Lee E, Michalkiewicz M, Kitlinska J, Kalezic I, Switalska H, Yoo $\mathrm{P}$, et al. Neuropeptide $\mathrm{Y}$ induces ischemic angiogenesis and restores function of ischemic skeletal muscles. J Clin Invest. (2003) 111:185362. doi: 10.1172/jci16929

82. Li L, Najafi A, Kitlinska J, Neville R, Laredo J, Epstein S, et al. Of mice and men: neuropeptide $\mathrm{Y}$ and its receptors are associated with atherosclerotic lesion burden and vulnerability. J Cardiovasc Transl Res. (2011) 4:35162. doi: 10.1007/s12265-011-9271-5

83. Li L, Jönsson-Rylander A, Abe K, Zukowska Z. Chronic stress induces rapid occlusion of angioplasty-injured rat carotid artery by activating neuropeptide Y and its Y1 receptors. Arterioscl Thromb Vasc Biol. (2005) 25:207580. doi: 10.1161/01.Atv.0000179601.19888.19

84. Csordas A, Bernhard D. The biology behind the atherothrombotic effects of cigarette smoke. Nat Rev Cardiol. (2013) 10:21930. doi: $10.1038 /$ nrcardio. 2013.8

85. Myers A, Abi-Younes S, Zukowska-Grojec Z. Re-evaluation of the effects of neuropeptide Y on aggregation of human platelets. Life Sci. (1991) 49:5451. doi: 10.1016/0024-3205(91)90072-j

86. Cippitelli A, Rezvani A, Robinson J, Eisenberg L, Levin E, Bonaventure $\mathrm{P}$, et al. The novel, selective, brain-penetrant neuropeptide $\mathrm{Y}$ Y2 receptor antagonist, JNJ-31020028, tested in animal models of alcohol consumption, relapse, and anxiety. Alcohol. (2011) 45:567-76. doi: 10.1016/j.alcohol.2010.09.003

87. Maddatu J, Anderson-Baucum E, Evans-Molina C. Smoking and the risk of type 2 diabetes. Transl Res. (2017) 184:101-7. doi: 10.1016/j.trsl.2017.02.004

88. Calarco C, Lee S, Picciotto M. Access to nicotine in drinking water reduces weight gain without changing caloric intake on high fat diet in male C57BL/6J mice. Neuropharmacology. (2017) 123:21020. doi: 10.1016/j.neuropharm.2017.06.012

89. Zhu P, Zhang Z, Huang X, Liang S, Khandekar N, Song Z, et al. RANKL reduces body weight and food intake via the modulation of hypothalamic NPY/CART expression. Int J Med Sci. (2018) 15:96977. doi: 10.7150/ijms. 24373

90. Wan X, Zeng F, Huang X, Yang H, Wang L, Shi Y, et al. Risperidone stimulates food intake and induces body weight gain via the hypothalamic arcuate nucleus 5-HT2c receptor-NPY pathway. CNS Neurosci Therap. (2020) 26:558-66. doi: 10.1111/cns.13281

91. Engström Ruud L, Pereira $M$, de Solis A, Fenselau H, Brüning J. NPY mediates the rapid feeding and glucose metabolism regulatory functions of AgRP neurons. Nat Commun. (2020) 11:442. doi: 10.1038/s41467-020-14291-3

92. Eva C, Oberto A, Longo A, Palanza P, Bertocchi I. Sex differences in behavioral and metabolic effects of gene inactivation: the neuropeptide Y and Y receptors in the brain. Neurosci Biobehav Rev. (2020) 119:33347. doi: 10.1016/j.neubiorev.2020.09.020

93. Duvall L, Ramos-Espiritu L, Barsoum K, Glickman J, Vosshall L. Smallmolecule agonists of aegypti neuropeptide y receptor block mosquito biting. Cell. (2019) 176:687-701. doi: 10.1016/j.cell.2018.12.004

94. Zhang L, Ip C, Lee I, Qi Y, Reed F, Karl T, et al. Diet-induced adaptive thermogenesis requires neuropeptide FF receptor-2 signalling. Nat Comm. (2018) 9:4722. doi: 10.1038/s41467-018-06462-0

95. Jang $M$, Shin M, Kim K, Cho S, Bahn G, Kim E, et al. Nicotine administration decreases neuropeptide $\mathrm{Y}$ expression and increases leptin receptor expression in the hypothalamus of food-deprived rats. Brain Res. (2003) 964:311-5. doi: 10.1016/s0006-8993(02)04122-7

96. van den Hoek A, van Heijningen C, Schröder-van der Elst J, Ouwens D, Havekes L, Romijn J, et al. Intracerebroventricular administration of neuropeptide $\mathrm{Y}$ induces hepatic insulin resistance via sympathetic innervation. Diabetes. (2008) 57:2304-10. doi: 10.2337/db07-1658
97. Sun W, Zhu P, Shi Y, Zhang C, Huang X, Liang S, et al. Current views on neuropeptide $\mathrm{Y}$ and diabetes-related atherosclerosis. Diabetes Vasc Dis Res. (2017) 14:277-84. doi: 10.1177/1479164117704380

98. Karunakaran U, Park K. A systematic review of oxidative stress and safety of antioxidants in diabetes: focus on islets and their defense. Diab Metab J. (2013) 37:106-2. doi: 10.4093/dmj.2013.37.2.106

99. Zhang Y, Zhang S, Khandekar N, Tong S, Yang H, Wang W, et al. Reduced serum levels of oestradiol and brain derived neurotrophic factor in both diabetic women and HFD-feeding female mice. Endocrine. (2017) 56:6572. doi: $10.1007 / \mathrm{s} 12020-016-1197-\mathrm{x}$

100. Avila-Carrasco L, Pavone M, González E, Aguilera-Baca Á, Selgas R, Del Peso G, et al. Abnormalities in glucose metabolism, appetiterelated peptide release, and pro-nflammatory cytokines play a central role in appetite disorders in peritoneal dialysis. Front Physiol. (2019) 10:630. doi: 10.3389/fphys.2019.00630

101. Javed F, Rahman I, Romanos G. Tobacco-product usage as a risk factor for dental implants. Periodontology. (2019) 81:48-56. doi: 10.1111/prd.12282

102. Lee S, Sanchez-Watts G, Krieger J, Pignalosa A, Norell P, Cortella A, et al. Loss of dorsomedial hypothalamic GLP-1 signaling reduces BAT thermogenesis and increases adiposity. Mol Metab. (2018) 11:3346. doi: 10.1016/j.molmet.2018.03.008

103. Horspool A, Chang H. Neuron-specific regulation of superoxide dismutase amid pathogen-induced gut dysbiosis. Redox Biol. (2018) 17:377-85. doi: 10.1016/j.redox.2018.05.007

104. Stafford J, Yu F, Printz R, Hasty A, Swift L, Niswender K. Central nervous system neuropeptide $\mathrm{Y}$ signaling modulates VLDL triglyceride secretion. Diabetes. (2008) 57:1482-90. doi: 10.2337/db07-1702

105. Dalvi P, Chalmers J, Luo V, Han D, Wellhauser L, Liu Y, et al. High fat induces acute and chronic inflammation in the hypothalamus: effect of high-fat diet, palmitate and TNF- $\alpha$ on appetite-regulating NPY neurons. Int $J$ Obesity. (2017) 41:149-58. doi: 10.1038/ijo.2016.183

106. Oda N, Miyahara N, Taniguchi A, Morichika D, Senoo S, Fujii $\mathrm{U}$, et al. Requirement for neuropeptide $\mathrm{Y}$ in the development of type 2 responses and allergen-induced airway hyperresponsiveness and inflammation. Am J Physiol Lung Cell Mol Physiol. (2019) 316:L407L17. doi: 10.1152/ajplung.00386.2018

107. Medzhitov R. Origin and physiological roles of inflammation. Nature. (2008) 454:428-35. doi: 10.1038/nature07201

108. McMahon D, Carey R, Kohanski M, Tong C, Papagiannopoulos $\mathrm{P}$, Adappa $\mathrm{N}$, et al. Neuropeptide regulation of secretion and inflammation in human airway gland serous cells. Europ Resp J. (2020) 55:1901386. doi: 10.1183/13993003.01386-2019

109. Fujiwara S, Hoshizaki M, Ichida Y, Lex D, Kuroda E, Ishii K, et al. Pulmonary phagocyte-derived NPY controls the pathology of severe influenza virus infection. Nat Microb. (2019) 4:258-68. doi: 10.1038/s41564-018-0 289-1

110. Liu Y, Yu J, Shi Y, Zhang Y, Lin S. The role of inflammation and endoplasmic reticulum stress in obesity-related cognitive impairment. Life Sci. (2019) 233:116707. doi: 10.1016/j.lfs.2019.116707

111. Chu S, Chen P, Yu C, Hsieh Y, Kuo D. Double immunofluorescent evidence that oxidative stress-associated activation of JNK/AP-1 signaling participates in neuropeptide-mediated appetite control. Europ Neuropsych. (2019) 29:1235-249. doi: 10.1016/j.euroneuro.2019.08.301

112. Warthen K, Sanford B, Walker K, Jones K, Angstadt M, Sripada $\mathrm{C}$, et al. Neuropeptide $\mathrm{Y}$ and representation of salience in human nucleus accumbens. Neuropsychopharmacology. (2019) 44:495-502. doi: 10.1038/s41386-018-0230-6

113. Rylkova D, Boissoneault J, Isaac S, Prado M, Shah H, Bruijnzeel A. Effects of NPY and the specific Y1 receptor agonist [D-His(26)]-NPY on the deficit in brain reward function and somatic signs associated with nicotine withdrawal in rats. Neuropeptides. (2008) 42:215-7. doi: 10.1016/j.npep.2008.03.004

114. Robinson S, Thiele $\mathrm{T}$. The role of neuropeptide $\mathrm{Y}$ (NPY) in alcohol and drug abuse disorders. Int Rev Neurob. (2017) 136:177-97. doi: 10.1016/bs.irn.2017.06.005

115. Gonçalves J, Martins J, Baptista S, Ambrósio A, Silva A. Effects of drugs of abuse on the central neuropeptide Y system. Addict Biol. (2016) 21:75565. doi: $10.1111 / \mathrm{adb} .12250$ 
116. Sato N, Kageyama S, Chen R, Suzuki M, Mori H, Tanioka F, et al. Association between neuropeptide $\mathrm{Y}$ receptor 2 polymorphism and the smoking behavior of elderly Japanese. J Hum Genet. (2010) 55:75560. doi: 10.1038/jhg.2010.108

117. Kuo L, Abe K, Zukowska Z. Stress, NPY and vascular remodeling: implications for stress-related diseases. Peptides. (2007) 28:435-40. doi: 10.1016/j.peptides.2006. 08.035

118. Singh P, Hoggatt J, Kamocka M, Mohammad K, Saunders M, Li H, et al. Neuropeptide Y regulates a vascular gateway for hematopoietic stem and progenitor cells. J Clin Invest. (2017) 127:4527-4540. doi: 10.1172/jci 94687

119. Park M, Min W, Jin H, Bae J. Role of neuropeptide $Y$ in the bone marrow hematopoietic stem cell microenvironment. BMB reports. (2015) 48:6456. doi: 10.5483/bmbrep.2015.48.12.22
120. Aerts-Kaya F, Ulum B, Mammadova A, Köse S, Aydin G, Korkusuz P, et al. Neurological regulation of the bone marrow niche. Adv Exp Med Biol. (2020) 1212:127-53. doi: 10.1007/5584_2019_398

Conflict of Interest: The authors declare that the research was conducted in the absence of any commercial or financial relationships that could be construed as a potential conflict of interest.

Copyright (C) 2021 Zheng, Wang, Li, Lin and Lin. This is an open-access article distributed under the terms of the Creative Commons Attribution License (CC BY). The use, distribution or reproduction in other forums is permitted, provided the original author(s) and the copyright owner(s) are credited and that the original publication in this journal is cited, in accordance with accepted academic practice. No use, distribution or reproduction is permitted which does not comply with these terms. 